\title{
Current Possibilities of Treatment in Pelvic-Perineal Floor Dysfunctions
}

\section{Simona Niculescu ${ }^{1 *}$, Ana Maria Enăchescu², Dan Niculescu² and Mircea Onofriescu ${ }^{3}$}

${ }^{1}$ Department of Obstetrics and Gynecology, 3rd Obstetrics and Gynecology Unit, Elena Doamna Hospital of Obstetrics and Gynecology, Gr.T. Popa University of Medicine and Pharmacy lassi, Romania

${ }^{2}$ Department of Surgery, St. Spiridon Hospital laşi, Romania

${ }^{3}$ Department of Obstetrics and Gynecology, 3rd Obstetrics and Gynecology Unit, Cuza Vodă Hospital of Obstetrics and Gynecology, Gr.T. Popa University of Medicine and Pharmacy laşi, Romania

\begin{abstract}
To support through personal experience the use on a large scale of the modern techniques of correction of the pelvic floor disorders by using polypropylene prosthetic devices.

Objectives: To specify the technical details regarding the correct placement of prostheses in feminine genital prolapse. Show the personal casuistry in order to highlight the indications techniques and results of these types of surgeries. Plead for expending the modern techniques in pelvic-perineal floor dysfunctions.

Material and Methods: The study was performed between July 2007 and July 2013, in the second surgical Clinic St.Spiridon Hospital lasi, on 138 cases with different pelvic floor dysfunctions. Different procedures were practiced, isolated or associated, on the patients in the lot, depending on symptoms, the prolapse type and degree, age, local anatomical situation and the existence or absence of sexual life. Thus they were performed: strip urethrocystopexy or "hammock" device, with four arms transobturator - 68 cases; The sacrosciatic posterior colposuspension or the anal levator floor restoration-29 cases; abdominal colpopexy in 41 cases, 18 of which with hysterectomy or resection of residual cervix. In 5 cases a polypropylene mesh implant has been associated with this procedure at anal levator level; and in 11 cases the doctors used a suburethral transobturator vaginal strip for stress urinary incontinence (SUI). The abdominal approach allows the correct path of skeletonization of the internal genitalia and also of the vagina which is turned inside-out like a glove finger, avoiding damage on the ureters and bladder. The vaginal vault is secured to the promontory with a polypropylene device and it ensures the results maintain in time.
\end{abstract}

Results: The treatment of the different pelvic-perineal floor disorders that are associated or not with stress urinary incontinence has benefited lately from new indications and techniques by using different prosthetic devices made of polypropylene, which are especially conceived and placed through minimally invasive procedures. Generally, all the cases had an immediate simple postoperatory evolution with only two haematomas that required surgical evacuation and 3 cases of vaginal mucosa necrosis, one of them requiring the removal of the device implanted. The anatomical and functional results were good.

Conclusions: The use of strips, nets and polypropylene devices in correcting different pelvic floor disorders, shows certain advantages, as it is relatively easy tom implement, the hospitalization period is shortened and there are very good results that pass the test of time.

Keywords: Pelvic-perineal floor dysfunctions; Stress urinary incontinence; Prosthetic devices

\section{Introducere}

Tulburările de statică pelviperineală apar prin deplasarea organelor susținute în mod normal de planșeul pelviperineal, perete vaginal anterior, uter, bolta vaginală, perete vaginal posterior, eventual antrenând și organele învecinate - vezică urinară, uretră , rect [1].

\section{Bump et al consideră [2]:}

- Prolaps de compartiment anterior - coborârea joncțiunii uretrovezicale la mai puțin de $3 \mathrm{~cm}$ deasupra inelului himeneal.

- Prolaps de compartiment mijlociu - coborârea bolții vaginale la mai puțin de $2 \mathrm{~cm}$ de inelul himeneal.

- Prolaps de compartiment posterior cu coborârea - jumătății peretelui vaginal posterior la mai puțin de $3 \mathrm{~cm}$ de inelul himeneal [3].

Deseori acestor tulburări de statică pelviperineală li se asociază incontinența urinară de efort (IUE) [4].

Scopul acestei lucrări este de a sustine prin experienta personală a utilizării pe scară cât mai largă a tehnicilor moderne de corectare a tulburărilor de statică pelviperineală prin protezare cu dispozitive de polipropilenă.

\section{Material și metodă}

În perioada Iulie 2007-Iulie 2013 au fost rezolvate prin protezări diverse un număr de 138 de cazuri cu diferite tulburări de statică pelvină. La bolnavele cuprinse în lot sau practicat izolat sau asociat diferite procedee în funcție de diagnostic, simptomatologie, tipul și gradul prolapsului, vârsta, situație anatomică locală, existența sau nu a vieții sexuale.

Diagnosticul a fost stabilit prin anamneză, examen clinic, ecografie și probe funcționale. Anamneza a evaluat:

*Corresponding author: Simona Niculescu, MD, PhD, Elena Doamna Obstetrics and Gynecology Hospital, lasi, Elena Doamna Street, No 29, 700398, Iasi, Romania, Tel: +40 (0) 2322103 90; E-mail: enachescu_anamaria@yahoo.com

Received January 29, 2014; Accepted November 23, 2014; Published November 29, 2014

Citation: Niculescu S, Enăchescu AM, Niculescu D, Onofriescu D. [Current Possibilities of Treatment in Pelvic-Perineal Floor Dysfunctions]. Journal of Surgery [Jurnalul de chirurgie] 2015; 10(4): 301-304 DOI:10.7438/1584-9341-10-4-13 [article in Romanian]

Copyright: (c) 2015 Niculescu S, et al. This is an open-access article distributed under the terms of the Creative Commons Attribution License, which permits unrestricted use, distribution, and reproduction in any medium, provided the original author and source are credited. 
factorul declanșator - nașteri, intervenții chirurgicale, menopauza, accidente neurologice,

vechimea tulburării,

gradul de invaliditate, răsunetul socioprofesional și sexual,

evoluția în timp a simptomatologiei,

tratamente efectuate anterior.

Examenul clinic, principalul nostru mijloc de diagnostic a fost efectuat în ortostatism și în poziție ginecologică, cu ambele valve dar mai ales cu o singură valvă folosind manevre cunoscute pentru provocarea pierderii de urină sau care sa simuleze corecția chirurgicală a incontinenței [5].

Diagnosticul cuprinde în afară de evaluarea biologica generală, dimensionarea ecografică a poziției joncțiunii vezico-uretrale, examenul citobacteriologic vaginal, urocultură, stabilirea în final a riscului anestezico- chirurgical [5].

Uretrocistopexia transobturatorie $[6,7]$ s-a realizat pe cale vaginală printr-o incizie longitudinală pe peretele anterior al vaginului, până la $1 \mathrm{~cm}$ de meat urmată de disecția laterală a peretelui vaginal și vezicii urinare până la eliberarea marginii inferioare a găurii obturatorii.

O mica incizie de $3 \mathrm{~mm}$ situată la $3-4 \mathrm{~cm}$ de linia mediană, aproximativ la mijlocul distanței dintre meat si clitoris, permite introducerea perforatorului ghid dinafară-înauntru străbătând membrana obturatorie la rasul marginii osoase superioare a ramului ischiopubian, până în vagin prin breșa special pregătita. Aici este atașat brațul protezei care este tras apoi dinăuntru-înafara și exteriorizat transobturator la tegument [8]. Procedând similar de partea controlaterală o bandeletă suburetrală este montată si peretele vaginal poate fi închis prin surget continuu de fir lent rezorbabil, după verificarea hemostazei.

Pentru amplasarea unui dispozitiv cu patru brațe în "hamac" suburetral, intervenția urmează aceeași pasi [9] doar că disecția laterală a peretelui vaginal se face pe o lungime mai mare, cu eliberarea marginii ischio-pubiene pe o lungime mai mare iar la tegument se mai face o mica incizie la aproximativ $4 \mathrm{~cm}$ mai jos de prima, ce va permite perforatorului sa străbată din nou membrana obturatorie pentru exteriorizarea brațului "hamacului" de polipropilenă. Dispozitivul se tensionează treptat prin tracțiuni pe brațele exteriorizate la piele si având în vedere respectarea unui spațiu de $2 \mathrm{~mm}$ suburetral [10]. Închiderea plăgii vaginale se face similar ca în cazul bandeletei simple.

Colposuspensia posterioară reprezintă soluția optimă pentru prolapsul de compartiment posterior. Prin incizia longitudinală a peretelui vaginal posterior se disecă lateral cu evidențierea peretelui rectal până la ridicatori și se împinge rectul către partea mediană progresiv în sus până la evidențierea spinei sciatice și sub aceasta a ligamentului sacrosciatic. Printr-o mică incizie situată la $4 \mathrm{~cm}$ lateral de anus, se introduce perforatorul ghid prin spațiu pararectal creat cu străbaterea ligamentului sacrosciatic și apoi cu ancorarea și tragerea dinăuntru-înafară a brațului dispozitivului protetic de polipropilenă. Acesta are forma unui "maieu" ale cărui "bretele" se exteriorizează cu ajutorul perforatorului paraanal drept și stâng, marginea superioară fiind fixată la limita colpocervicală posterioară iar marginea inferioară eventual ajustată, la centrul de rezistență perineală. Hemostaza si închiderea tranșei vaginale finalizează procedeul.

Nu în ultimul rând, informarea completă a bolnavei este obligatorie si consimțământul informat al acesteia este semnat pe un formular special conceput.

\section{Rezultate și discuții}

În ceea ce priveste vârsta, bolnavele au fost încadrate între 30 si 85 de ani cu predominanță clară a decadelor V, VI, VII, în peste 50\% din cazuri.

La bolnavele noastre am apreciat gradul de incontinență ca fiind:

gradul I - la efort brusc (manevra Valsalva) în 21 de cazuri,

gradul II - în ortostatism sau la efort mare (ridicări greutăți , alergare, etc.) în 27 de cazuri,

gradul III incontinența în repaus (clino sau ortostatism) în 20 de cazuri (Figura 1).

Ca indicație apropiată fiecărei situații, la bolnavele din lotul menționat, au fost realizate următoarele procedee:

Uretrocistopexie cu bandeletă sau dispozitiv "in hamac" cu patru brațe transobturator - 68 de cazuri,

Colposuspensie posterioară (Figura 2) sacrosciatică sau uneori colpoperineorafie posterioară cu refacerea planșeului ridicătorilor anali - 29 de cazuri,

Colpopromontopexia cu proteză de polipropilenă pe cale abdominală - 41 de cazuri.

Colpopromontopexia pe cale abdominală a fost efectuată in 41 de cazuri dintre care $18 \mathrm{cu}$ histerectomie sau rezecția colului restant. În 11 dintre aceste cazuri a asociat amplasarea pe cale vaginală a unei bandelete transobturatorii pentru incontinență și în alte 5 cazuri a fost amplasată și o proteză trapezoidală la mușchii ridicători anali evidențiați retrovaginal. Prezența colului uterin în cazurile de prolaps de boltă vaginală posthisterectomie subtotală au impus (dupa test Papanicolau) ablația acestuia. Preferăm rezolvarea acestor cazuri prin abord abdominal care permite [11] scheletizarea corectă a uterului sau/și a colului restant cu evitarea lezării ureterovezicale. Abordul abdominal [12] urmează gesturi standardizate.

După visceroliză în miculbazin cu separarea fundului de sac Douglas, de obicei aderent pe vechea cicatrice și separarea bontului colului uterin restant anterior de peretele vezical și posterior de peretele rectal se disecă bontul vaginal în absenta colului, este de obicei mai dificilă și trebuie realizată cu hemostază progresivă și intercepția vaselor din plexurile cervicovaginale pe măsură ce acestea sunt întâlnite. Vaginul se scheletizează pe o porțiune, care ajunge anterior până în apropierea joncțiunii vezicouretrale posterior până la evidențierea completă a

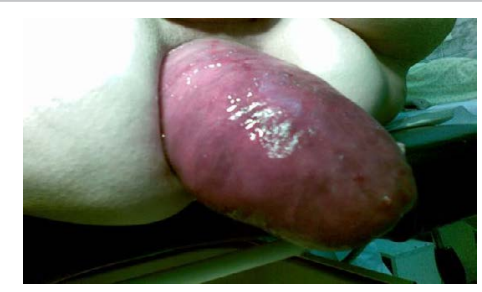

Figura 1: Prolaps genital total.

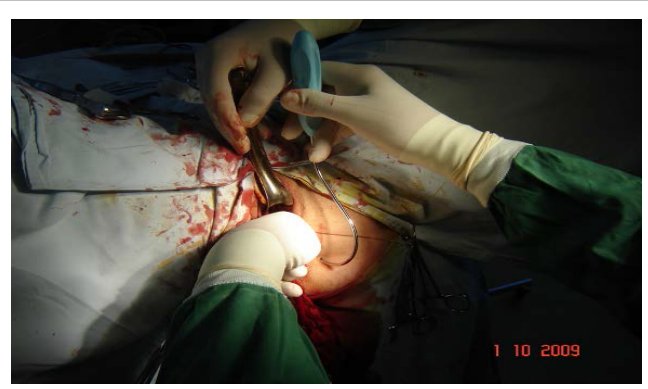

Figura 2: Prolaps compartiment posterior introducere "tuneller" pentru suspensie sacrosciatica. 
marginilor musculare, a diafragmului urogenital și a ridicătorilor anali. Lateral, scheletizarea va intercepta eventualele bonturi ligamentare (ligamente rotunde sau/ şi utero-sacrate) va evidenția ureterele terminale care trebuie cu grija evitate și dacă este cazul se va relua ligatura și rezecția pediculilor vasculari uterini. Lungimea bontului vaginal astfel creat este foarte diferită de la un caz la altul, impunând colpohisterectomie sau totalizare histerectomie pentru situațiile cu col uterin restant. Tranșa vaginală se sutureză cu dublu surget continuu de material foarte lent resorbabil (preferabil monofilamentar). După ce bontul vaginal este astfel pregătit și eliberat circumferențial pe circa $2 \mathrm{~cm}$ înălțime, se reperează promontoriul, lateral dreapta de peretele rectal se incizeaz[ pe $2-3 \mathrm{~cm}$ peritoneul parietal posterior deasupra promontoriului și se diseca un tunel subperitoneal care lasă medial peretele rectal, menajează lateral ureterul și in partea inferioară parcurge baza ligamentelor largi până când se detașează complet rectul și se evidențiază bontul vaginal. Tunelul astfel creat se reperează printr-o meșă care completează hemostaza și îl menține accesibil timpilor următori. Se pregătește proteza de polipropilenă pentru suspendarea colpopromontorială aceasta realizându-se prin croirea dintr-o plasă obişnuită de protezare parietală a unui dispozitiv în formă de diapazon sau $\mathrm{T}$ inversat, a cărui ramuri orizontale înconjoară și se fixează pe fața anterioară și posterioară a bontului vaginal ( folosim două rânduri de puncte separate cu fir neresorbabil, monofilamentar 3-0 ). Brațul vertical situat la marginea dreaptă si posterioară a bontului vaginal se ascensionează prin tunelul subperitoneal creat anterior. Brațul vertical al protezei se ridică până la nivelul feței anterioare a promontoriului si lungimea sa se ajusteaz astfel încât bontul vaginal să fie bine ascensionat și susținut fără însă a tensiona excesiv montajul. Fixarea capătului superior al dispozitivului o facem cu patru puncte de fir nerezorbabil la periostul promontorial ( câte doua puncte de fiecare parte a bandeletei). După controlul riguros al hemostazei și poziției rectului față de implant, breșa peritoneală se închide și cu alt fir se peritonizează zona parametrilor disecaţi. Uneori înainte de închiderea peritoneală inferioară , este posibilă plasarea unui implant la nivelul marginii ridicătorilor anali fixat inferior la centrul tendinos și care va intări peretele vaginal posterior în porțiunea sa inferioară. Închiderea tranșei peritoneale va realiza concomitent și o ascensionare a fundului de sac Douglas până deasupra nivelului tranșei vaginale. La sfârșitul intervenției se controlează pe cale vaginală poziția actuală a vaginului și dacă este necesar se poate adăuga pe această cale o bandeletă suburetrală pentru incontinența urinară.

Această intervenție comportă riscuri chirurgicale de mică importanță și cu o corectă îngrijire pre, intra și post-operatorie poate fi folosită cu succes chiar și la bolnavele înaintate în vârstă.

In corectarea prolapsului de compartiment anterior si a incontinentei urinare, rezultatele au fost bune si foarte bune cu mici complicații intra si postoperatorii (2 hematoame, 2 necroze de mucoasa vaginală și o supurație care a impus tardiv suprimarea protezei).

In prolapsul de compartiment posterior evoluție foarte bună și fără complicații semnificative.

In prolapsul compartimentului mijlociu rezultatele în general au fost bune, amintind doar 3 cazuri, unde postoperator s-a instalat o incontinență urinară care a impus după 30 de zile efectuarea intervenției complementare de plasare pe cale vaginală a unei bandelete suburetrale transobturatorii.

Spitalizarea postoperatorie a fost în medie de 10 zile, iar controalele ulterioare la 2, 6 și 12 luni au demonstrat evoluția favorabilă din punct de vedere anatomic si functional.

Societatea Internațională de Continență încadrează ca IUE „relatarea oricărei pierderi involuntare de urină” (2002). Se apreciază că aproximativ $30 \%$ din populația feminină prezintă pierderi involuntare de urină [13].
Tratamentul prolapsului genital asociat cu IUE a beneficiat în timp de peste 100 de procedee imaginate [14]:

- Tehnici de susținere (colporafia anterioara, plicatura suburetrala Kelly, Marion 1914)

- Suspensia transvaginală a colului vezical ( Pereyra 1950, Raz, Stamey, Gittes.)

- Suspensie retropubiană (Burch 1961, Marshall - Marchetti Krantz 1949 ).

- Suspensie cu bandelete suburetrale pubovaginale (T.V.T ) și transobturatorii (T.O.T).

Actual indicații și tehnici noi utilizează diferitele dispozitive protetice de polipropilenă special concepute în corectarea diverselor tulburări de statică pelvină izolate sau asociate cu o eventuală incontinență urinară [15].

Marea majoritate a tehnicilor de plasare a acestor dispozitive sunt minim invazive cu exceptia abordului abdominal pentru colpopromotopexie.

In afara de rata mică a complicaţiilor utilizarea acestor tehnici ofera rezultate anatomice si functionale bune și persistente în timp [16].

\section{Concluzii}

Evoluția favorabilă imediată și la distanță a cazurilor confirmă utilizarea tehnicilor diferențiat, adaptate fiecarui caz în parte și susține ideea că folosirea în tratamentul incontinenței urinare de efort și a tulburărilor de statică pelvină a diferitelor dispozitive de polipropilenă prin tehnica minim invazivă este deplin justificată.

\section{Conflict de interese}

Autorii nu declară nici un conflict de interese

\section{References}

1. Pricop M (2006) Gynaecological surgery. Institutul European lasi Publishing House 136-148.

2. Bump RC, Mattiasson A, Bø K, Brubaker LP, DeLancey JO, et al. (1996) The standardization of terminology of female pelvic organ prolapse and pelvic floor dysfunction. Am J Obstet Gynecol 175: 10-17.

3. Barbulea-Raducea E (2003) The standardization of terminology of female pelvic organ prolapse and pelvic floor dysfunction (POP-Q). Rom J Urogynec Pelvic Floor Disord 1: 41-54.

4. Bumbu G (2006) Screening - Incontinence. Urinary disorders. Prolapse. The Romanian Magazine of Uro-Gynecology 1.

5. Bumbu G (2007) Practical Uro-Gynecology. Oradea 107-147, 153-213.

6. Bumbu G, Maghiar TT, Szilagy L, et al. (2006) Transobturatory approach and intra-coccigeal sacropexy with polypropylene mesh for high grade urogenital and vault prolapse. Abstract book - XV Congresso Nazionale Perugia.

7. Bratila P, Nicodin O, Barbulea-Raducea E (2004) Transvaginal sling procedure for urinary incontinence due to intrinsic sphincterian deficiency. Rom $\mathrm{J}$ Urogynec Pelvic Floor Disord 1: 29-32.

8. Spinosa JP, Dubuis PY, Riederer B (2005) [Transobturator surgery for female urinary continence: from outside to inside or from inside to outside: a comparative anatomic study]. Prog Urol 15: 700-706.

9. Deval B, El Houari Y, Rafii A, Levardon M (2002) [Pubo vaginal and sub urethral slings: review]. J Gynecol Obstet Biol Reprod (Paris) 31: 131-143.

10. Paick JS, Oh JG, Shin JW, Kim SW, Ku JH (2007) Significance of tension in tension-free mid-urethral sling procedures: a preliminary study. Int Urogynecol J Pelvic Floor Dysfunct 18: 153-158.

11. Nichols DH (1997) Central compartment defects. Philadelphia PA: Lippincott Raven 8: 1006-1030.

12. Toozs-Hobson $P$, Boos $K$, Cardozo $L$ (1998) Management of vaginal vault prolapse. Br J Obstet Gynaecol 105: 13-17.

13. Bumbu G (2007) Indicatii chirurgicale actuale in incontinenta urinara de efort si prolaps urogenital. 
14. Petri E (1999) Micro-invasive surgical techniques for the treatment of urogynaecological disorders: traditional procedures. Perspectives in Gynaecology and Obstetrics 43-47.

15. Robert M, Farrell SA, Easton WA, Epp A, Flood CG, et al. (2005) Choice of surgery of stress incontinence. J Obstet Gynaecol Can 27: 964-980.
16. Morey AF, Medendorp AR, Noller MW, Mora RV, Shandera KC, et al. (2006) Transobturator versus transabdominal mid urethral slings: a multi-institutional comparison of obstructive voiding complications. J Urol 175: 1014-1017. 